\title{
Phylogenetic Origins of Early Alterations in Brain Region Proportions
}

\author{
Christine J. Charvet ${ }^{a}$ Alexis L. Sandoval ${ }^{a}$ Georg F. Striedter ${ }^{a} b$ \\ a Department of Neurobiology and Behavior and Center for the Neurobiology of Learning and Memory, \\ University of California, and ${ }^{b}$ Department of Ecology and Evolutionary Biology, University of California, \\ Irvine, Calif., USA
}

\section{Key Words}

Bird - Development - Mammal • Monotreme - Reptile •

Tectum • Vision

\begin{abstract}
Adult galliform birds (e.g. chickens) exhibit a relatively small telencephalon and a proportionately large optic tectum compared with parrots and songbirds. We previously examined the embryonic origins of these adult species differences and found that the optic tectum is larger in quail than in parakeets and songbirds at early stages of development, prior to tectal neurogenesis onset. The aim of this study was to determine whether a proportionately large presumptive tectum is a primitive condition within birds or a derived feature of quail and other galliform birds. To this end, we examined embryonic brains of several avian species (emus, parrots, songbirds, waterfowl, galliform birds), reptiles (3 lizard species, alligators, turtles) and a monotreme (platypuses). Brain region volumes were estimated from serial Nisslstained sections. We found that the embryos of galliform birds and lizards exhibit a proportionally larger presumptive tectum than all the other examined species. The presumptive tectum of the platypus is unusually small. The most parsimonious interpretation of these data is that the expanded embryonic tectum of lizards and galliform birds is a derived feature in both of these taxonomic groups.
\end{abstract}

Copyright $\odot 2010$ S. Karger AG, Base

\section{Introduction}

Adult brains vary in the proportions of their major regions [Stephan et al., 1981; Boire and Baron, 1994; Barton and Harvey, 2000; Iwaniuk et al., 2004; Iwaniuk and Hurd, 2005; Reep et al., 2007; Yopak et al., 2007]. Most studies examining the developmental origins of species differences in brain region size focus on the telencephalon. These studies have shown that the expansion of the telencephalon is usually, though not always, achieved through delays in neurogenesis [Finlay and Darlington, 1995; Finlay et al., 1998; Clancy et al., 2001; Finlay et al., 2001; Striedter and Charvet, 2008; Charvet and Striedter, 2009a, b]. The developmental origins of variations in the size of other brain structures, such as the optic tectum, have received less scrutiny. However, we have previously shown that, in birds, species differences in the size of the optic tectum are evident early in development [Striedter and Charvet, 2008]. Specifically, we found the optic tectum is proportionally larger in bobwhite quail than in parakeets or songbirds before tectal neurogenesis begins [Striedter and Charvet, 2008; Charvet and Striedter, 2009a].

Whether the large size of the embryonic quail's optic tectum is a primitive feature for birds or a derived feature remains unclear. Galliform birds are a basal clade of neognathous birds [Hackett et al., 2008], but not all galliform characteristics are necessarily primitive. To re-

\section{KARGER}

Fax +41613061234 E-Mail karger@karger.ch www.karger.com
() 2010 S. Karger AG, Basel www.karger.com/bbe
Christine Charvet

100 Qureshey Research Laboratory

Department of Neurobiology and Behavior, University of California, Irvine Irvine, CA 92687-4550 (USA)

Tel. +1 949824 4248, Fax +1 949824 2447, E-Mail ccharvet@ uci.edu 

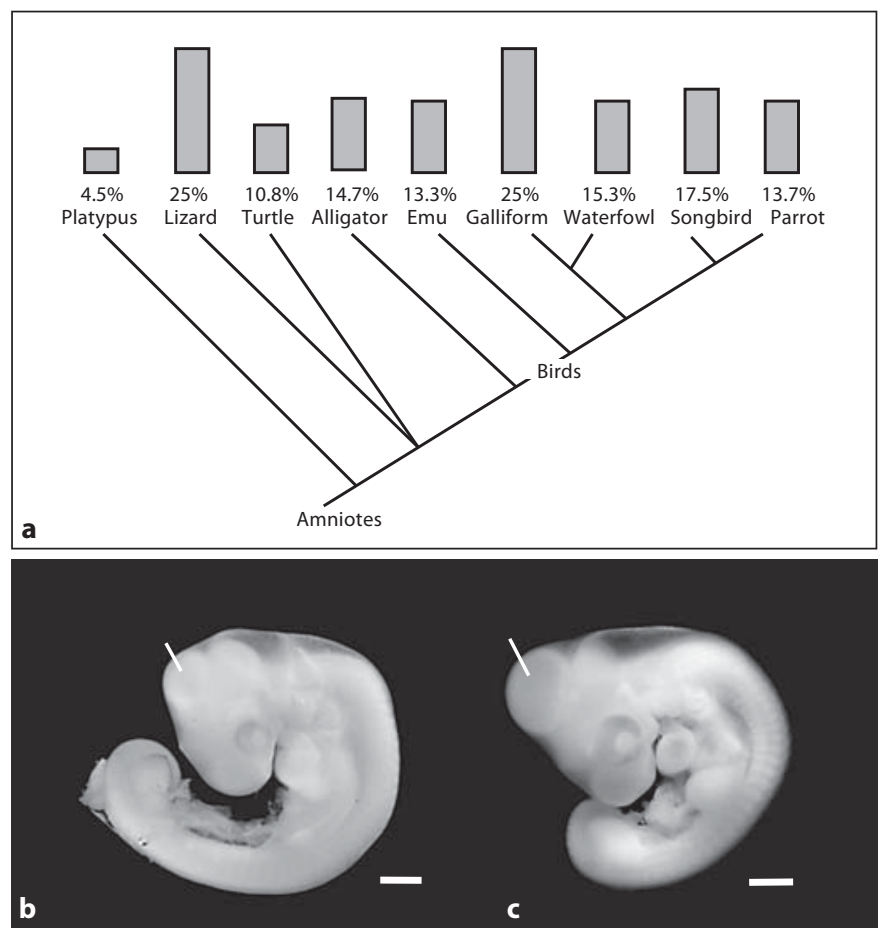

Fig. 1. a Variations in presumptive tectum size mapped onto a phylogeny of amniotes [Meyer and Zardoya, 2003; Hackett et al., 2008]. The gray bars indicate the average size of the presumptive tectum in early embryos of the indicated taxonomic groups. The major conclusion of the present study is that galliform birds (chickens, turkeys, quail) and lizards (chameleons, wall lizards, skinks) exhibit a proportionally larger presumptive tectum than the other examined species. The photographs in (b) and (c) respectively show an emu embryo at embryonic day 8 and a chicken embryo at day 4 . The white lines point to the presumptive tectum. Scale bars $=1 \mathrm{~mm}$.

solve whether the quail's large tectum is derived or primitive, we measured the proportional size of the pre-neurogenetic (i.e. presumptive) optic tectum in embryos of additional galliform birds (chickens, turkeys), waterfowl (ducks, geese), songbirds (finches, sparrows), a parrot (parakeets), a paleognathous bird (emus), reptiles (turtles, chameleons, wall lizards, skinks, alligators), and a monotreme (platypuses; see fig. 1a; table 1). We found that galliform birds and lizards exhibit a proportionally enlarged presumptive optic tectum compared to turtles, alligators, emus and platypuses. Given the phylogenetic relationships of these species (fig. 1a), we conclude that the size of the presumptive optic tectum probably increased independently in galliform birds and lizards. In other words, tectal enlargement is a derived feature in these two taxonomic groups.

\section{Materials and Methods}

Nissl-stained sections of embryonic platypuses (Ornithorhynchus anatinus), lizards (chameleons, Chameleo bitaeniatus; wall lizards, Podarcis muralis; skinks, Mabuya megalura), snapping turtles (Chelydra serpentina), emus (Dromaius novaehollandiae) and house sparrows (Passer domesticus) from the Hubrecht and Hill collection [see Richardson and Narraway, 1999; Giere and Zeller, 2005; Carter, 2008] were photographed at the Museum für Naturkunde in Berlin, Germany (table 1). Fertilized parakeet (Melopsittacus undulatus), zebra finch (Taeniopygia guttata), emu (Dromaius novaehollandiae), alligator (Alligator mississippiensis), galliform (chicken, Gallus gallus domesticus; bobwhite quail, Colinus virginianus; turkey, Meleagris gallopavo) and waterfowl (mallard duck, Anser platyrhynchos; greylag goose, Anser anser) eggs were incubated in our laboratory (table 1). Some of these embryos were used in previous studies [Striedter and Charvet, 2008; Charvet and Striedter, 2009a, b].

\section{Laboratory Specimens}

Specimens were collected at ages when the presumptive tectum is morphologically identifiable (fig. $1 b, c)$ but does not exhibit a post-proliferative zone (i.e. before tectal neurogenesis onset). Because the age of alligator embryos was difficult to verify, their ages were inferred from the embryo's developmental stage [Ferguson, 1985] (table 1). Collected embryos were immersed overnight in methacarn and stored in $70 \%$ ethanol. The embryos were embedded in paraffin and sectioned horizontally at $20 \mu \mathrm{m}$. 20-60 regularly spaced sections from each specimen were stained with Giemsa and photographed.

\section{Museum Specimens}

Nissl-stained sections of museum specimens were placed on a light box and photographed with a 40D Canon camera equipped with a $65-\mathrm{mm}$ MP-E macro lens (1-4X). Because embryos from the Hill and Hubrecht collection probably shrank to various degrees, we compare only proportional brain region sizes across specimens. Because stage information for some museum specimens was difficult to verify, we assessed the maturity of each specimen by examining its brain. Only specimens that exhibited a morphologically identifiable tectum lacking a post-proliferative zone were included in our analysis.

\section{Morphometric Analysis}

Regularly spaced sections were used to estimate presumptive tectum and overall brain volumes by summing the cross-sectional areas and multiplying by the section spacing. Regions of interest were outlined in each section and area measurements were made using the software program ImageJ [Rasband, 1997-2007]. We focus on the optic tectum, which we define as excluding the torus semicircularis and the tectal gray, in order to facilitate comparisons with previous analyses of adult brains [Boire and Baron, 1994; Iwaniuk and Hurd, 2005]. We defined the presumptive tectum by the presence of a uniformly thick ventricular zone, caudal to the thicker tegmentum. Because this definition matches our previous one [Striedter and Charvet, 2008; Charvet and Striedter, 2009a, b], we combine the present data with that from our previous research. The presumptive tectum fraction was calculated by dividing the presumptive tectum volume by the overall brain volume. 
Table 1. Studied specimens and their approximate ages or stages

\begin{tabular}{|c|c|c|c|}
\hline Collected specimens & $\mathrm{n}$ & $\begin{array}{l}\text { Embryonic day (ED) } \\
\text { or stage }\end{array}$ & $\begin{array}{l}\text { Age expressed as a } \% \\
\text { of incubation period }\end{array}$ \\
\hline American alligator (Alligator mississippiensis) & 4 & $\begin{array}{l}\text { Stages } 14-16 \\
\text { (estimated ED 16-21) }\end{array}$ & $25.5-29$ \\
\hline \multicolumn{4}{|l|}{ Paleognaths } \\
\hline Emu (Dromaius novaehollandiae) & 5 & ED 7-13 & $14-26$ \\
\hline \multicolumn{4}{|l|}{ Galliform birds } \\
\hline Chicken (Gallus gallus domesticus)* & 9 & ED 3-6 & $14.3-28.6$ \\
\hline Bobwhite quail (Colinus virginianus)* & 4 & ED $4.4-6$ & $19.1-26.1$ \\
\hline Turkey (Meleagris gallopavo)* & 7 & ED $5-7$ & $17.8-25$ \\
\hline \multicolumn{4}{|l|}{ Waterfowl } \\
\hline Mallard duck (Anser platyrhynchos)* & 11 & ED 4-7 & $15.4-26.9$ \\
\hline Greylag goose (Anser anser)* & 8 & ED 5-8 & $16.6-26.6$ \\
\hline \multicolumn{4}{|l|}{ Parrots } \\
\hline Parakeet (Melopsittacus undulatus)* & 6 & ED $4.5-7$ & $25-38.9$ \\
\hline \multicolumn{4}{|l|}{ Songbirds } \\
\hline Zebra finch (Taeniopygia guttata)* & 7 & ED $4-7$ & $28.6-50$ \\
\hline Museum specimens & $\mathrm{n}$ & Museum specimen No. & Collection \\
\hline \multicolumn{4}{|l|}{ Birds } \\
\hline Emu (Dromaius novaehollandiae) & 2 & A204, A208 & Hill \\
\hline House sparrow (Passer domesticus)* & 6 & $9,11,14,51,69, \mathrm{~A} 132$ & Hill \\
\hline \multicolumn{4}{|l|}{ Turtles } \\
\hline Snapping turtle (Chelydra serpentina) & 3 & $\mathrm{~S} 1, \mathrm{~S} 2, \mathrm{~S} 3$ & Hubrecht \\
\hline \multicolumn{4}{|l|}{ Lizards } \\
\hline Side-striped chameleon (Chameleo bitaeniatus) & 4 & C9-a, C6-b, C5-a, 1001 & Hubrecht \\
\hline Wall lizard (Podarcis muralis) & 2 & M127; M83 & Hubrecht \\
\hline Skink (Mabuya megalura) & 3 & $1,2,5$ & Hubrecht \\
\hline \multicolumn{4}{|l|}{ Monotremes } \\
\hline Platypus (Ornithorhynchus anatinus) & 5 & 87,55, M38, M40, M41 & Hill \\
\hline
\end{tabular}

Most specimens were collected in our laboratory; others were examined in museum collections. The sex of the specimens is unknown. Specimens marked with an asterisk were used also in previous studies [Striedter and Charvet, 2008; Charvet and Striedter, 2009a, b]. For the analysis of laboratory specimens it proved useful to express embryonic age not simply in terms of physical time (i.e. embryonic days) but as a percentage of the species' normal incubation period [Charvet and Striedter 2009b, c].

Statistical Analysis

The presumptive tectum fraction changes little over the course of embryonic development in several avian species [Striedter and Charvet, 2008; Charvet and Striedter, 2009a, b]. To confirm that the presumptive tectum fraction is constant in our species, we performed a linear regression on each species' data set and subjected it to an ANOVA. We previously found that tectal neurogenesis timing is highly predictable once age is expressed as a percentage of normal incubation time in some precocial species [Charvet and Striedter, 2009b, c]. We, therefore, express age as a percentage of the species' normal incubation period. Such a comparison showed that the presumptive optic tectum fraction increased with age only in chickens ( $\mathrm{p}=0.016, \mathrm{~F}=9.99, \mathrm{n}=9$; table 2 ) but even this increase was small (fig. 2a). Therefore, we combined data from different embryonic ages for all our species. Statistical com- parisons were made both across species and between orders. Because neither the species nor the orders showed unequal variances, we subjected the data to ANOVAs and pair-wise honest significant difference Tukey tests. All statistical analyses were performed with the software program JMP (SAS, Cary, N.C., USA).

To determine whether museum specimens and collected specimens would yield similar results, we compared the embryonic tectum size of emus from the museum and those we collected. We found that the presumptive tectum volume fraction of emus from the museum $(\overline{\mathrm{x}}=14.6 \%$; SEM $=2.4 ; \mathrm{n}=2)$ and the embryos collected in our laboratory $(\overline{\mathrm{x}}=12.8 \%$; $\mathrm{SEM}=0.81 ; \mathrm{n}=5)$ are highly similar. These observations suggest that museum and collected specimens yield comparable results. 
Table 2. Results from an analysis of variance for tectum volume fraction versus embryonic age (expressed as percentage of each species' normal incubation period)

\begin{tabular}{llrrrr}
\hline Species & Embryonic day (ED) & $\mathrm{n}$ & $\mathrm{a}$ & $\mathrm{R}^{2}$ & $\mathrm{~F}$ and $\mathrm{p}$ values \\
\hline Alligator (Alligator mississipiensis) & Stages 14-16 (ED 16-21) & 4 & -0.42 & 0.13 & $\mathrm{~F}=0.31 ; \mathrm{p}=0.63$ \\
Emu (Dromaius novaehollandiae) & ED 7-13 & 5 & -0.07 & 0.04 & $\mathrm{~F}=0.12 ; \mathrm{p}=0.75$ \\
Chicken (Gallus gallus domesticus) & ED 3-6 & 9 & 0.51 & 0.59 & $\mathrm{~F}=9.99 ; \mathrm{p}<0.05 ; \mathrm{p}=0.02$ \\
Bobwhite quail (Colinus virginianus) & ED 4.4-6 & 4 & 0.60 & 0.64 & $\mathrm{~F}=3.57 ; \mathrm{p}=0.12$ \\
Turkey (Meleagris gallopavo) & ED 5-7 & 7 & 0.11 & 0.02 & $\mathrm{~F}=0.10 ; \mathrm{p}=0.77$ \\
Mallard duck (Anser platyrhynchos) & ED 4-7 & 11 & 0.13 & 0.05 & $\mathrm{~F}=0.52 ; \mathrm{p}=0.49$ \\
Greylag goose (Anser anser) & ED 5-8 & 8 & 0.20 & 0.20 & $\mathrm{~F}=1.55 ; \mathrm{p}=0.26$ \\
Parakeet (Melopsittacus undulatus) & ED 4.5-7 & 6 & 0.11 & 0.07 & $\mathrm{~F}=0.31 ; \mathrm{p}=0.61$ \\
Zebra finches (Taeniopygia guttata) & ED 4-7 & 7 & -0.14 & 0.31 & $\mathrm{~F}=2.24 ; \mathrm{p}=0.19$
\end{tabular}

Only in chickens did the size of the presumptive tectum (at ages prior to tectal neurogenesis onset) significantly increase with age, and even this increase was relatively mild. 'a' refers to the slope of the linear regression.

\section{Results}

The presumptive tectum fraction differs significantly between species (d.f. $=14 ; \mathrm{F}=26.08 ; \mathrm{p}<0.0001$ ) and between orders (d.f. $=8 ; \mathrm{F}=34.81 ; \mathrm{p}<0.0001$; fig 2b). Pairwise post-hoc comparisons between orders show that the presumptive tectum fraction is significantly larger in galliform birds $(\overline{\mathrm{x}}=25.05 \%$; SEM $=0.87 ; \mathrm{n}=20)$ and lizards $(\overline{\mathrm{x}}=25.01 \% ; \mathrm{SEM}=1.03 ; \mathrm{n}=9)$ than in all other orders we examined (fig. $2 \mathrm{~b}$; table 3 ). The presumptive tectum volume fraction is significantly smaller in monotremes $(\overline{\mathrm{x}}=4.49 \%$; SEM $=0.82 ; \mathrm{n}=5)$ than in all other orders except turtles $(\overline{\mathrm{x}}=10.77 \%$; SEM $=0.93 ; \mathrm{n}=3$; fig. $2 \mathrm{~b}$; table 3).

Pair-wise comparisons between species yielded similar results, except that the zebra finch's presumptive tectum fraction $(\overline{\mathrm{x}}=19.37 \%$; SEM $=0.97 ; \mathrm{n}=7)$ was not significantly different from that of turkeys $(\overline{\mathrm{x}}=21.78 \%$; SEM $=1.01 ; \mathrm{n}=7)$, skinks $(\overline{\mathrm{x}}=24.13 \%$; $\mathrm{SEM}=1.40 ; \mathrm{n}=$ $6)$, chameleons $(\overline{\mathrm{x}}=24.43 \%$; $\mathrm{SEM}=2.40 ; \mathrm{n}=4)$ or wall lizards $(\overline{\mathrm{x}}=27.50 \%$; SEM $=2.5 ; \mathrm{n}=2$; table 3$)$. The presumptive tectum fraction of the platypus is the smallest of all examined species, ranging between 2.6 and $6.9 \%$.

To determine how the embryonic presumptive tectum fraction relates to adult tectum size we compared our embryonic data to previously published data on adult tectum size in galliform birds, waterfowl, parrots and songbirds [Ebinger and Löhmer, 1987; Boire and Baron, 1994; Iwaniuk and Hurd, 2005]. We found that the embryonic presumptive tectum fraction is 2.2-3.4 times larger than the adult tectum fraction. Importantly, plotting embryonic presumptive tectum fraction against adult tectum frac- tion (fig. $2 \mathrm{c}$ ) yields a strong positive correlation $\left(\mathrm{R}^{2}=\right.$ $0.814, \mathrm{p}<0.05 ; \mathrm{n}=8$ ). This finding shows that the embryonic variation in optic tectum size we describe persists, at least to some extent, into adulthood.

\section{Discussion}

The optic tectum is a major sensorimotor integration region in non-mammalian vertebrates [Comer and Grobstein, 1981], and birds exhibit considerable variation in the size of the optic tectum in adulthood and in development [Boire and Baron, 1994; Iwaniuk and Hurd, 2005]. This was particularly evident in a previous study, in which we found the presumptive tectum to be proportionately larger in quail than in parrots and songbirds [Charvet and Striedter, 2009a]. To address whether the quail's large optic tectum is a primitive or a derived feature, we broadened our comparative analysis to include basal lineages of birds (i.e. emus), reptiles and a monotreme.

We combined data from laboratory and museum specimens. This is potentially problematic because the two groups were likely fixed differently, causing the tissue to shrink to different degrees. Restricting our comparisons to proportional rather than absolute brain region volumes minimized this problem. Supporting evidence for this approach is that our estimate of the presumptive tectum fraction of emus was nearly identical for the museum and laboratory specimens.

One potential limitation of our study is that the embryos varied slightly in age. However, the presumptive 
Fig. 2. a Presumptive tectum fraction (expressed as a percentage of brain volume) plotted against embryonic age. In order to control for species differences in maturation rate, embryonic age is expressed as a percentage of the species' normal incubation time. Previous analyses showed that neurogenesis onset is highly predictable in several precocial species once age is expressed as a percentage of normal incubation period [Charvet and Striedter, 2009b, c]. Specifically, the presumptive optic tectum becomes morphologically identifiable at approximately $14 \%$ of the normal incubation period and tectal neurogenesis onset occurs roughly around $30 \%$ of normal incubation period in the examined precocial species. b Histograms of the mean presumptive tectum fraction for each examined species plotted along with individual data points show that the optic tectum is proportionally enlarged in galliform birds and lizards compared with the other species we examined. c Scatterplot of embryonic tectum fraction versus adult tectum fraction for 8 species in which both adult and embryonic data were available, together with the regression line.

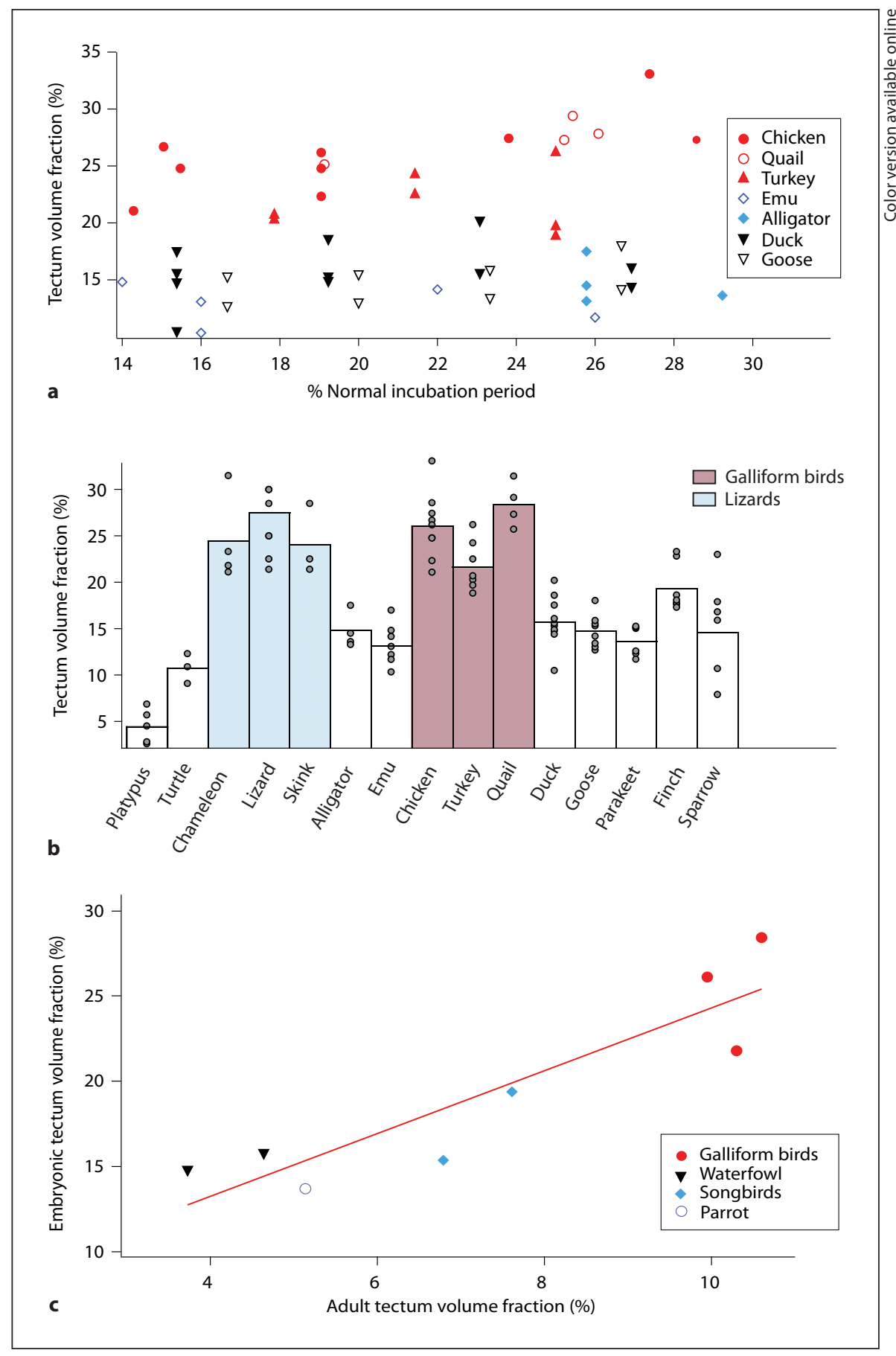

tectum fraction varies little during the brief embryonic period we examined (fig. 2a). This is unlike most other brain structures, which grow at different rates relative to overall brain size [Striedter and Charvet, 2008]. For example, the size of the eye changes considerably relative to overall brain size over the course of embryonic develop- ment, making cross-species comparisons of eye size difficult [unpublished observations].

The study's major finding is that galliform birds and lizards exhibit a proportionately larger presumptive optic tectum than other birds, other reptiles, and monotremes. The presumptive tectum is significantly smaller in platy- 
Table 3. Data summary by taxonomic order and species

\begin{tabular}{|c|c|c|c|c|c|c|c|c|c|}
\hline & Mean pre- & Standard & $\mathrm{n}$ & & $\mathrm{D} \mathrm{Tu}$ & akey & test & & \\
\hline & & & & & & & & & \\
\hline Galliform birds & 25.05 & 0.87 & 20 & A & & & & & \\
\hline Lizards & 25.01 & 1.03 & 9 & $\mathrm{~A}$ & & & & & \\
\hline Songbirds & 17.52 & 1.23 & 13 & & B & & & & \\
\hline Waterfowl & 15.35 & 0.51 & 19 & & $\mathrm{~B}$ & $\mathrm{C}$ & & & \\
\hline Alligators & 14.69 & 0.99 & 4 & & B & $\mathrm{C}$ & & & \\
\hline Parrots & 13.67 & 0.66 & 6 & & B & $\mathrm{C}$ & & & \\
\hline Paleognaths & 13.33 & 0.84 & 7 & & B & $\mathrm{C}$ & & & \\
\hline Turtles & 10.77 & 0.93 & 3 & & & $\mathrm{C}$ & $\mathrm{D}$ & & \\
\hline Monotremes & 4.49 & 0.82 & 5 & & & & $\mathrm{D}$ & & \\
\hline Species & & & & & & & & & \\
\hline Bobwhite quail & 28.42 & 1.23 & 4 & A & & & & & \\
\hline Wall lizard & 27.50 & 2.50 & 2 & A & B & $\mathrm{C}$ & & & \\
\hline Chicken & 26.10 & 1.18 & 9 & A & B & & & & \\
\hline Chameleon & 24.43 & 2.40 & 4 & A & B & $\mathrm{C}$ & & & \\
\hline Skink & 24.13 & 1.40 & 6 & A & B & $\mathrm{C}$ & & & \\
\hline Turkey & 21.78 & 1.01 & 7 & & B & $\mathrm{C}$ & & & \\
\hline Zebra finch & 19.37 & 0.97 & 7 & & & $\mathrm{C}$ & $\mathrm{D}$ & & \\
\hline Mallard duck & 15.77 & 0.75 & 11 & & & & $\mathrm{D}$ & $\mathrm{E}$ & \\
\hline House sparrow & 15.37 & 2.20 & 6 & & & & $\mathrm{D}$ & $\mathrm{E}$ & \\
\hline Greylag goose & 14.76 & 0.63 & 8 & & & & $\mathrm{D}$ & $\mathrm{E}$ & \\
\hline Alligator & 14.69 & 0.99 & 4 & & & & $\mathrm{D}$ & E & \\
\hline Parakeet & 13.67 & 0.66 & 6 & & & & $\mathrm{D}$ & $\mathrm{E}$ & \\
\hline Emu & 13.33 & 0.84 & 7 & & & & & $\mathrm{E}$ & \\
\hline Snapping turtle & 10.77 & 0.93 & 3 & & & & & $\mathrm{E}$ & $\mathrm{F}$ \\
\hline Platypus & 4.49 & 0.82 & 5 & & & & & & $\mathrm{~F}$ \\
\hline
\end{tabular}

The right column describes the results of pair-wise honest significant difference (HSD) Tukey tests for all orders (top) and all species (bottom). Orders or species that are not connected by the same capital letter have significantly different mean presumptive tectum fractions $(\mathrm{p}<0.05)$. For instance, the presumptive tectum fraction of songbirds is significantly different only from that of galliform birds, lizards, turtles and monotremes.

pus than in all other examined species except turtles. Given the phylogenetic relationship of these species (fig. 1a), parsimony leads us to conclude that the presumptive tectum increased at least twice independently: once in galliform birds and once in the lineage leading to lizards. Whether or not the presumptive tectum decreased in the lineage leading to the platypus cannot be determined because we have no quantitative data on embryonic tectum size of embryonic anamniotes.

Among mammals, we examined only the platypus, but many features of this species are highly derived. The observation that the platypus is a highly aquatic mammal and closes its eyes underwater [Pettigrew et al., 1998] suggests that the platypus makes little use of its vision. Therefore, the presumptive superior colliculus size of the platypus may be a derived feature within mammals. However, our preliminary observations of some embryonic placental mammals (i.e. rabbits, Oryctolagus cuniculus, and tarsiers, Tarsius bancanus) in the Hubrecht and Hill collection suggest that the presumptive superior colliculus in these species is more similar to that of the platypus than that of the non-mammalian amniotes we examined. This suggests that the presumptive superior colliculus of mammals is generally smaller than the presumptive optic tectum of reptiles and birds. However, further research is required to test this hypothesis.

Our findings pertain to embryos, but they relate to, and explain, species differences in adult tectum size. The tectum occupies $\sim 10 \%$ of the brain in adult galliform birds, but only $4.6-7.6 \%$ in adult waterfowl, parrots, and songbirds [Ebinger and Löhmer, 1987; Iwaniuk and Hurd, 2005]. These species differences in adult tectum size are less obvious than variations in adult telencephalon size. Early in embryogenesis, species differences in tectum size are more apparent because telencephalic and cerebellar neurogenesis is protracted. As a result, the telencephalon and cerebellum expand late in development [Finlay and Darlington, 1995; Striedter and Charvet, 2008; Charvet and Striedter, 2009a].

Given that species differences in the size of the optic tectum are observed prior to tectal neurogenesis onset, the observed variations in adult tectum size cannot be due to species differences in tectal neurogenesis timing [Striedter and Charvet, 2008]. Most likely, the species differences in the size of the optic tectum arise because of alterations in brain patterning and/or early differences in proliferation rates [Araki and Nakamura, 1999; Matsunaga et al., 2001; Nakamura, 2001; Menuet et al., 2007; Rétaux et al., 2008]. Further research is required to determine the developmental mechanisms underlying the expansion of the presumptive tectum in galliform birds and lizards.

\section{Acknowledgments}

We are very grateful to Dr. Peter Giere for help at the Naturkunde Museum. We thank Drs. Tomasz Owerkowicz and Michael Pritz for alligator embryos, and Dr. Susana Cohen-Cory for feedback on the manuscript. We thank Dr. David Weisbart for sharing his camera equipment and Johnny Huang for help with photography. This work was supported by a NSF IOS-0744332 and a DAAD grant A-07-74197. 


\section{References}

-Araki I, Nakamura H (1999): Engrailed defines the position of dorsal di-mesencephalic boundary by repressing diencephalic fate. Development 126:5127-5135.

Barton RA, Harvey PH (2000): Mosaic evolution of brain structure in mammals. Nature 405: 1055-1058.

Boire D, Baron G (1994): Allometric comparison of brain and main brain subdivisions in birds. J Brain Res 35:49-66.

Carter AM (2008): Sources of comparative studies of Placentation. 1. Embryological collections. Placenta 29:95-98.

Charvet CJ, Striedter GF (2009a): Developmental origins of mosaic brain evolution: morphometric analysis of the developing zebra finch brain. J Comp Neurol 514:203-213.

Charvet CJ, Striedter GF (2009b): Developmental basis for telencephalon expansion in waterfowl: enlargement prior to neurogenesis. Proc Biol Sci 276:3241-3247.

Charvet CJ, Striedter GF (2009c): Neurogenesis timing is conserved across precocial avian specie. Soc Neurosci Abstr 225:6.

Clancy B, Darlington RB, Finlay BL (2001): Translating developmental time across mammalian species. Neuroscience 105:7-17.

-Comer C, Grobstein P (1981): Organization of sensory inputs to the midbrain of the frog Rana pipiens. J Comp Physiol 142:161-168.

-Ebinger P, Löhmer R (1987): A volumetric comparison of brains between greylag geese ( $A n$ ser anser L.) and domestic geese. J Hirnforsch 3:291-299.

- Finlay BL, Darlington RB (1995): Linked regularities in the development and evolution of mammalian brains. Science 268:1578-1584.
Finlay BL, Darlington RB, Nicastro N (2001): Developmental structure in brain evolution. Behav Brain Sci 24:263-308.

-Finlay BL, Hersman MN, Darlington RB (1998): Patterns of vertebrate neurogenesis and the paths of vertebrate evolution. Brain Behav Evol 52:232-242.

Ferguson MWJ (1985): Reproductive biology and embryology of the crocodilians; in Gans C, Billet F Maderson PFA (eds): Biology of the Reptilia: Development A. New York, Wiley, vol 14, pp 329-491.

Giere P, Zeller U (2005): Transfer of the Hubrecht Laboratory Collection from Utrecht to the Museum für Naturkunde, Berlin. Placenta 26:A15.

- Hackett SJ, Kimball RT, Reddy S, Bowie RC, Braun EL, Braun MJ, Chojnowski JL, Cox WA, Han KL, Harshman J, Huddleston CJ, Marks BD, Miglia KJ, Moore WS, Sheldon FH, Steadman DW, Witt CC, Yuri T (2008): A phylogenomic study of birds reveals their evolutionary history. Science 320:1763-1768.

Iwaniuk AN, Dean C, Nelson JE (2004): A mosaic pattern characterizes the evolution of the avian brain. Proc R Soc Lond B Suppl 271: $148-151$

Iwaniuk AN, Hurd PL (2005): The evolution of cerebrotypes in birds. Brain Behav Evol 65: 215-230.

Matsunaga E, Araki I, Nakamura H (2001): Role of $\mathrm{Pax} 3 / 7$ in the tectum regionalization. Development 128:4069-4077.

Menuet A, Alunni A, Joly JS, Jeffrey WR, and Rétaux S (2007): Expanded expression of Sonic Hedgehog in Astyanax cavefish: multiple consequences on forebrain development and evolution. Development 134:845855 .
Meyer A, Zardoya R (2003): Recent advances in the (molecular) phylogeny of vertebrates. Ann Rev Ecol Evol Syst 34:311-338.

Nakamura H (2001): Regionalization of the optic tectum: combinations of gene expression that define the tectum. Trends Neurosci 24: 32-39.

Pettigrew JD, Manger PR, Fine SLB (1998): The sensory world of the platypus. Phil Trans R Soc Lond B 353:1199-1210.

Rasband WS (1997-2007): ImageJ. Bethesda, National Institutes of Health.

Reep RL, Finlay BL, Darlington RB (2007): The limbic system in mammalian brain evolution. Brain Behav Evol 70:57-70.

Rétaux S, Pottin K, Alunni A (2008): Shh and forebrain evolution in the blind cavefish Astyanax mexicanus. Biol Cell 100:139-147.

Richardson MK, Narraway J (1999): A treasure house of comparative embryology. Int J Dev Biol 43:591-602.

Stephan H, Frahm H, Baron G (1981): New and revised data on volumes of brain structures on insectivores and primates. Folia Primatol 35:1-29.

Striedter GF, Charvet CJ (2008): Developmental origins of species differences in telencephalon and tectum size: morphometric comparisons between a parakeet (Melopsittacus undulatus) and a quail (Colinus virgianus). J Comp Neurol 507:1663-1675.

Yopak KE, Lisney TJ, Collin SP, Montgomery JC (2007): Variation in brain organization and cerebellar foliation in chondrichthyans: sharks and holocephalans. Brain Behav Evol 69:280-300. 